\title{
FRAGMENTOS DA HISTÓRIA DA GINÁSTICA RÍTMICA NO RIO GRANDE DO SUL: AS PRIMEIRAS PROFESSORAS E SUAS MEMÓRIAS
}

\author{
Johanna Coelho von Mühlen \\ Universidade Federal do Rio Grande do Sul, Porto Alegre, Rio Grande do Sul, \\ Brasil

\section{Daniela Natividade} \\ Universidade Federal do Rio Grande do Sul, Porto Alegre, Rio Grande do Sul, \\ Brasil

\section{Silvana Vilodre Goellner} \\ Universidade Federal do Rio Grande do Sul, Porto Alegre, Rio Grande do Sul, \\ Brasil
}

\begin{abstract}
Resumo
A Ginástica Rítmica vem sendo desenvolvida no Brasil desde 1953 e no Rio Grande do Sul desde o início da década de 1970. Considerando os poucos registros sobre a história da modalidade, esta pesquisa tem como objetivo descrever seus primórdios a partir da memória de quatro professoras identificadas como pioneiras no trabalho com esta modalidade neste Estado. Fundamentada no aporte teóricometodológico da História Oral, foram realizadas entrevistas e, dos seus diálogos com outras fontes de pesquisa, identificamos não apenas a atuação das professoras mas sobretudo as estratégias adotadas para a divulgação e legitimação desta prática nas escolas de ensino fundamental e cursos de formação de profissionais de Educação Física.
\end{abstract}

Palavras-chave: Educação Física e Treinamento. Ginástica. História.

\section{Introdução}

Oom o objetivo de "realizar um estudo sobre a dinâmica de desenvolvimento do esporte, educação física e atividades físicas de saúde e lazer na perspectiva de suas categorias centrais de importância regional" (MAZO, 2005) foi publicado, no ano de 2005, o do Atlas do Esporte no Rio Grande do Sul. Ao percorrer suas páginas, nos deparamos com a seguinte referência:

No Rio Grande do Sul, a GR foi introduzida em 1972, pela bailarina e professora da Escola de Educação Física do Instituto Porto Alegre - ESEF-IPA, Vera Lucia Zamberlan Angheben. 
Neste mesmo ano, em Santos - SP, Angheben participou do curso de Ginástica Feminina Moderna, ministrado pela professora húngara Ilona Peuker, radicada no Rio de Janeiro, e principal responsável pela divulgação da GR no Brasil. Neste curso também estavam presentes Zelira Eichemberg, professora de Educação física do Colégio Anchieta, Porto Alegre - RS, e Rita Pozzobon Xisto, professora das escolas de Santa Maria - RS (FONTANA, NAGAMINE, 2005, p. 30)

Instigadas por tal registro e, cientes da falta de publicações sobre os primórdios da Ginástica Rítmica (GR) ${ }^{1}$ no estado do Rio Grande do Sul (RS), buscamos reconstruir sua história a partir da narrativa de algumas mulheres que protagonizaram essa história: as primeiras técnicas da modalidade, em grande medida, responsáveis pela sua expansão e divulgação no início da década de 1970.

Entendendo que as práticas corporais e esportivas constituem as referências identitárias de pessoas, grupos e instituições, percebemos como importante o registro de suas memórias na medida em que possibilitam conhecer dados de um tempo já transcorrido colaborando, sobremaneira, para entender o presente, não no sentido de justificálo, mas de buscar várias possíveis respostas aos diversos questionamentos que hoje podemos empreender (GOELLNER et al., 2007). Nesse sentido, ao buscarmos as narrativas das primeiras técnicas de GR no Rio Grande do Sul, não estamos propondo contar sua história mas, sobretudo, conferir voz e visibilidade àquelas cuja trajetória pessoal e profissional deixaram marcas nos modos como essa modalidade esportiva figurou no cenário cultural gaúcho.

Para tanto buscamos fundamentação teórico-metodológica na História Oral, que possibilita recorrer, como fonte básica de consulta, a depoimentos de pessoas cujas trajetórias relacionam-se com o objeto de estudo. Cientes dessa premissa entrevistamos quatro professoras de Educação Física, consideradas como pioneiras da GR no Estado². As entrevistas foram gravadas e, posteriormente, processadas conforme

1-A modalidade já teve outras denominações Ginástica Rítmica Desportiva, Ginástica Rítmica Moderna, Ginástica Feminina Moderna e Ginástica Moderna foram outras denominações adotadas ao longo da história (PALLARÉS, 1983, p.10).

2- Zelira Mendes Eichenberg, Vânia Viana, Margaret Biasi e Vera Lúcia Zamberlan Angheben. 
orientações do Projeto Garimpando Memórias do Centro de Memória do Esporte ${ }^{3}$. Vale lembrar ainda que os depoimentos das técnicas não foram observados como um relato fiel do que efetivamente ocorreu, mas como uma versão produzida pelas entrevistadas. Trabalhamos, portanto, com a reconstrução do vivido conforme o concebido por quem viveu.

Trabalhar com História Oral pressupõe trabalhar com memória isto é, com experiências individuais ou coletivas. Afinal, ainda que a memória seja guardada por um indivíduo tendo como referência suas experiências e vivências, essa memória está marcada pelo grupo social onde conviveu e se socializou e esse caráter social constitui-se em um elemento essencial da formação de sua identidade, da percepção que tem de si mesmo e dos outros. Cabe ressaltar, como bem expressou Rousso (1996, p. 95):

Se o caráter coletivo de toda a memória individual nos parece evidente, o mesmo não se pode dizer da idéia de que existe uma "memória coletiva", isto é, uma presença e portanto uma representação do passado que sejam compartilhadas nos mesmos termos por toda uma coletividade.

Assim como a entrevista está intimamente relacionada à memória, entendida como a capacidade humana de reter fatos e experiências do passado, seu processamento articula, simultaneamente, pesquisa e documentação visto que possibilita, também, a produção de um documento histórico. Daí sua riqueza pois "a evidência oral, transformando os "objetos" de estudo em "sujeitos", contribui para um história que não só é mais rica, mais viva e mais comovente, mas também mais verdadeira" (THOMPSON, 1992, p. 136). Não no sentido de que aquilo que está sendo relatado efetivamente aconteceu assim, mas de que há ali uma vida a ser exposta a partir de quem a viveu. Nessa perspectiva é que trabalhamos com os registros de memória das técnicas de GR do Rio Grande do Sul, buscando, sobretudo, minimizar a carência de estudos sobre o assunto.

3-Aprovado pelo Comitê de Ética da UFRGS sob o número 2007710. Maiores informações sobre o projeto podem ser encontradas em http://www.esef.ufrgs.br/ceme/projetos/garimpando/index.htm 
Uma vez realizada e processada cada entrevista, as colocamos em diálogo com outras fontes de pesquisa, tais como artigos, livros, almanaques, jornais, e registros iconográficos do período, em especial, aqueles que estão abrigados no acervo histórico do Centro de Memória do Esporte da Universidade Federal do Rio grande do Sul ${ }^{4}$. Como ferramenta metodológica foi utilizada a análise de conteúdo (BARDIN, 2000) a partir de três fases distintas: a pré-análise, na qual foi feita a organização das entrevistas eleitas para esse estudo. Nesse momento foram sistematizadas todas as respostas que fizessem referência ao início da GR no Estado. Posteriormente foi realizada a exploração desse material, caracterizada pela codificação a partir das unidades de registro. Desse procedimento resultou a etapa de tratamento dos dados, os quais foram categorizados, interpretados e colocados em diálogo com as outras fontes considerando os objetivos da pesquisa. Do entrecruzamento entre as entrevistas e os diferentes documentos analisados destacamos três temas: a) fragmentos históricos da modalidade; b) o início da GR no Rio Grande do Sul e c) competições, regras, aparelhos e músicas: primeiras exibições. É sobre esses três temas que discorremos nesse texto.

\section{Fragmentos históricos da Ginástica Rítmica}

Definida como uma "arte dinâmica, criativa, natural, orgânica com movimentos de características próprias diferentes de outras escolas de expressão corporal" (FEDERAÇÃO INTERNACIONAL DE GINÁSTICA, 2011, s.p,), a GR é considerada uma modalidade esportiva feminina, pois no nível competitivo é praticado somente por mulheres. "É um esporte arte que empolga, motivado pela competição e desejo de chegar à perfeição" (MOLINARI, 2004). Baseia-se não só na execução correta dos movimentos, mas também na graciosidade das atletas. Todos os elementos são associados entre si juntamente com o manejo dos aparelhos podendo a série ser realizada em conjunto ou individual. A prática oficial é realizada em uma quadra de tapete com amortecimento de impacto medindo $13 \times 13$ metros no qual as ginastas executam suas composições.

4-Em 2010 a professora Vera Lúcia Zamberlan Angheben doou parte de seu acervo particular para o Centro de Memória. Além desses documentos o acervo tem vários materiais provenientes de professoras de ginástica da Escola de Educação Física da UFRGS.

Pensar a Prática, Goiânia, v. 16, n. 1, p. 1-319, jan./mar. 2013

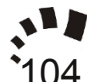


Segundo Garcia e Marconato (2005 p. 26) a ginástica é uma modalidade praticada desde o final da I Guerra Mundial, porém sem as regras e os métodos específicos que conhecemos hoje. Internacionalmente a primeira competição da modalidade ocorreu em 1948, na antiga Rússia. Nesse mesmo ano realizaram-se os Jogos Olímpicos de Londres nos quais a Ginástica Rítmica participou como esporte de demonstração porque oficialmente não era considerada uma modalidade olímpica (PALLARÉS, 1983, p.10). Foi no ano de 1984, que a GR foi reconhecida pelo Comitê Olímpico Internacional como modalidade de esporte oficial dos Jogos Olímpicos de Los Angeles (GARCIA E MARCONATO, 2005 p. 27).

Segundo Alonso e Ingeborge (2006, p.226), no Brasil a Ginástica Rítmica vem sendo desenvolvida desde 1953. Chegou ao Brasil por meio do trabalho da professora austríaca Margareth Frohlich, que veio para ministrar aulas de Ginástica Feminina Moderna no III Curso de Aperfeiçoamento Técnico e Pedagógico, promovido pelo Estado de São Paulo. Margareth Frohlich teve como assistente a professora Erica Sauer, então vinculada à Escola Nacional de Educação Física e Desportos da Universidade do Brasil, atual Escola de Educação Física e Desportos da Universidade Federal do Rio de Janeiro.

No mesmo ano de 1953 também chegou ao Rio de Janeiro, a professora húngura Ilona Peuker, que fundou o Grupo Unido de Ginastas (GUG) composto por meninas interessadas na prática da ginástica. Segundo Garcia e Marconato (2005, p.33), o objetivo desse grupo era divulgar a GR e aumentar o rol de participantes, para tanto ele realizava apresentações por diversos estados do país. Nos depoimentos e fontes consultadas não conseguimos acessar nenhuma informação sobre a presença do GUG no Rio Grande do Sul, no entanto, a estratégia de criar um grupo de ginástica inspirou a professora Vera Lúcia Zamberlan Angheben, uma das pioneiras da GR no Estado e fundadora do Grupo de Ginástica da ESEF-IPA, conhecido por GRUGIPA - um marco na história da modalidade no Sul do país.

\section{Primórdios da Ginástica Rítmica no Rio Grande do Sul}

No Rio Grande do Sul, segundo os registros encontrados nas fontes documentais e corroborados pelas entrevistadas, o primeiro contato que as gaúchas tiveram com a Ginástica Rítmica se deu no ano de 1972 quando quatro professoras deslocaram-se para a cidade de San- 
tos (São Paulo) com o objetivo de participar do I Curso de Férias oferecido pela Organização de Desporto e de Educação Física (ODEF). Dentre as disciplinas oferecidas no curso, estava a de Ginástica Feminina Moderna, ministrada pela professora Ilona Peuker, já radicada no Rio de Janeiro, e principal responsável pela divulgação da GR no Brasil. Deslocaram-se para Santos as professoras Vera Lúcia Zamberlan Angheben (Escola de Educação Física do Instituto Porto AlegreESEF-IPA), Quintina Cândida Marna Letícia Rachel Crocco Paccini (Escola Superior de Educação Física da Universidade Federal do Rio Grande do Sul), Zelira Mendes Eichenberg (Colégio Anchieta de Porto Alegre) e Rita Pozzobon Xisto (Rede Municipal de Ensino da cidade de Santa Maria). Segundo uma das entrevistadas:

$\mathrm{Na}$ verdade, esse curso era feito em São Paulo todos os anos pela ODEF. Esse órgão trazia varias modalidades, nessa época, inclusive a ginástica moderna. Minha professora de dança e ballet, Maria Gladis Dietrich, é que soube por carta e me convidou para fazer com ela. Ela ficou na área de dança e eu na ginástica porque eu estava começando a trabalhar dentro da ESEF do IPA justamente com a disciplina de ginástica, por isso eu fui para ginástica moderna. (ANGHEBEN E BIASI, 2010, p. 01)

De volta ao Estado as professoras que tiveram contato com a GR se envolveram na promoção de um Curso de Extensão de Ginástica Feminina Moderna realizado na Escola Superior de Educação Física da Universidade Federal do Rio Grande do Sul nos dias 17 a 22 de Julho de 1972 tendo como ministrante Ilona Peuker. Segundo os dados coletados, essa parece ter sido a primeira aparição da GR e, também, o primeiro contato que muitas professoras tiveram com esta modalidade ginástica. Neste curso várias participantes eram do interior do estado sendo que $[. .$.$] " o contato que foi feito com a UFRGS foi com a pro-$ fessora Quintina para trazer o curso da professora Ilona Peuker pra julho de 1972" (ANGHEBEN E BIASI, 2010, p. 01).

Os cursos ministrados por Ilona incentivavam a aplicação da Ginástica Moderna através de trabalhos tanto voltados para o desenvolvimento da ginástica em escolas e projetos, quanto para o que ela denominava de trabalho de elite, que tinha como finalidade difundir a Ginástica Moderna por meio de demonstrações e participações em competições. $\mathrm{O}$ trabalho nas escolas se caracterizava por ser a base, 
pois dele surgiriam as ginastas capazes de participar de grupos de elite. Portanto, seguindo a linha de trabalho de Ilona, as técnicas que realizaram o curso iniciaram o desenvolvimento da modalidade no Estado do Rio Grande do Sul seguiram a sua escola. (PEUKER, 1974).

Vera Lúcia Zamberlan Angheben, ao retornar do curso, selecionou algumas alunas e fundou o Grupo de Ginástica da Escola de Educação Física do Instituto Porto Alegre, (GRUGIPA), o primeiro que apareceu no sul do Brasil com tal característica. Na sua entrevista tece a seguinte narrativa:

[...] quando eu vi o que se podia fazer com uma corda e uma bola eu comecei a estudar as possibilidades de ser feito um trabalho assim, como na ESEF a gente já tava trabalhando eu recrutei o grupo de lá eu como professora de ginástica quem na verdade eu via com mais condições de trabalhar com aquilo ali, [...] mas nos tínhamos pessoas que não tinha nada a ver com a dança, $[. .$.$] e começaram a trabalhar com a ginástica, [\ldots]$ alunas da li que quisessem e outras que eu achava que tinha condições. (ANGHEBEN E BIASI, 2010, p. 01).

Os treinos do GRUGIPA eram realizados no ginásio ou nas salas ginásticas da faculdade, sempre de segunda a sexta-feira após o horário das aulas da graduação, ou seja, os treinos iniciavam as 22 horas e 50 minutos e finalizavam aproximadamente perto da 1 hora da madrugada (ANGHEBEN E BIASI, 2010, p.02). Nos finais de semana nos quais o Grupo não tinha apresentações, os encontros aconteciam aos sábados à tarde. $\mathrm{O}$ treinamento do grupo não era voltado somente para o desenvolvimento de suas coreografias, também eram trabalhados exercícios de flexibilidade, elementos corporais e aparelhos específicos, como saltos e lançamentos.

Em agosto de 1972, na comemoração do primeiro aniversário da ESEF-IPA, as alunas da Faculdade, dirigidas por Vera Angheben, realizaram a primeira apresentação de Ginástica Feminina Moderna do Estado do Rio Grande do Sul, a mãos livres e com o aparelho bola, conforme podemos ver na imagem abaixo: 


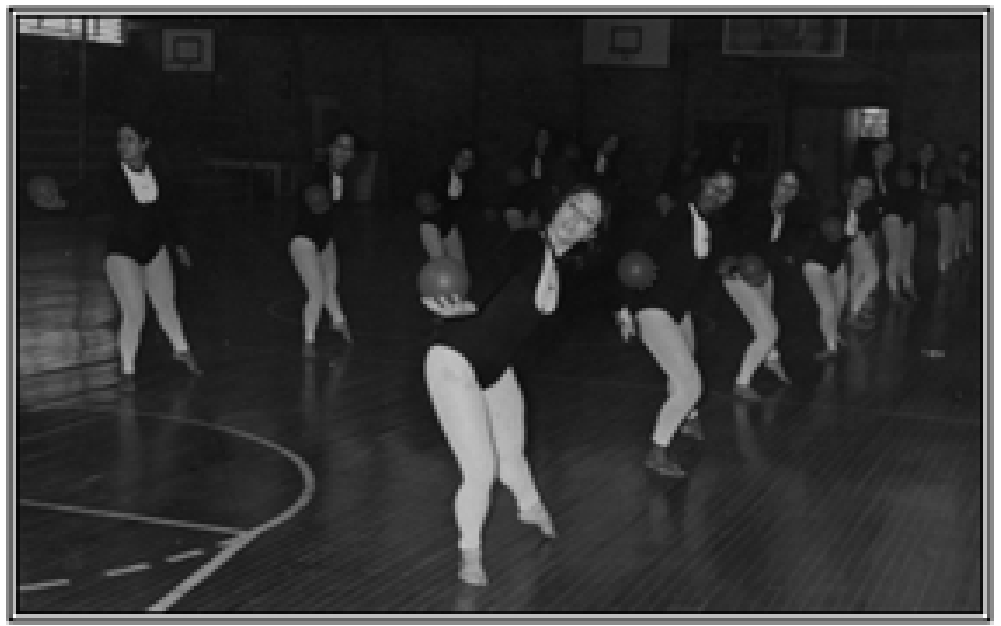

Foto 01: Demonstração de Ginástica Moderna no aniversário ESEF/IPA, ano de 1972. Fonte: ANGHEBEN, V. Demonstração de Ginástica Moderna no aniversário ESEF/IPA. 1972. Fotografia.

A partir daí, o GRUGIPA ${ }^{5}$ passou a realizar muitas apresentações em diversas cidades do interior do estado, no estado de Santa Catarina e algumas cidades do Uruguai. Utilizava, além dos aparelhos comuns da GR, alguns instrumentos regionais como pandeiros, tamboretes, lenços coloridos e faixas largas conferindo um caráter particular às coreografias.

Neste mesmo período em que o GRUGIPA estava sendo formado no IPA, a professora Zelira Mendes Eichenberg criava, dentro do Colégio Anchieta, uma escolhinha de Ginástica Moderna. Nas suas palavras:

[...]Foram os primeiros passos, engatinhando. Eu trabalhei mais na rede escolar com ginástica rítmica escolar, como era chamada. Não trabalhávamos com desportiva porque não tínhamos competições. (...) Meu objetivo, no primeiro, sempre foi o escolar. Era introduzir todos os que quisessem abrir a por-

5-Ao longo de quatros anos o GRUGIPA contou a presença de aproximadamente 25 ginastas de destaque no cenário da dança e da ginástica no RS tais como Margaret Biasi, Clause Krenzinger, Maria Valéria Baggio, Suzana Gutierrez, Eliane Masina, Tânia Mara Barcellos, Roseana Alves, Cleide Frazan Zanini, Sandra Schanes, Maria Cristina Villar, Laurita Alves, Maria Bernadette Ussan, Maria Valeska Zirbes, Margaret Ritter da Costa, Maria Aparecida Prieto, Sandra Shames, Jane Toniolo, Jane Elwanger, Maria Cristina Damelto, Lígia Azevedo. 
ta da ginástica para todas as crianças. Infelizmente, naquela época, só as meninas, porque depois nós queríamos trabalhar com os meninos, mas sempre com massificação. Todo mundo podia fazer sem nenhum objetivo maior. (EICHENBERG, 2010, p.1 e 10).

Contudo, com o início da modalidade dentro das escolinhas do Colégio, sentiu a necessidade de realizar um treinamento mais específico para as alunas que possuíam maior interesse e habilidade dentro do esporte. Foi desta maneira que surgiu uma equipe competitiva vinculada ao Colégio Anchieta, conduzida por Zelira do seguinte modo:

Eu já trabalhava com os pré-acrobáticos mesmo sem poder incluir, porque eu sabia que isso dava muita segurança para as ginastas. Tu poder colocar as mãos, erguer as pernas, os rolinhos iniciais para frente, para trás, [...] os pré-acrobáticos e a parada de mão. Eu achava importante para o equilíbrio. (EICHENBERG, 2010, p.6).

O grupo de ginastas formado no Colégio Anchieta, também realizava demonstrações de GR em escolas e clubes. Essas apresentações, em conjunto com as do GRUGIPA, despertavam a curiosidade dos que as assistiam, com isso a modalidade foi sendo divulgada de modo a proporcionar a sua inserção como um conteúdo curricular de cursos de graduação de Educação Física.

No ano de 1978, por exemplo, a Ginástica Rítmica foi introduzida no currículo do Curso de Licenciatura em Educação Física da Universidade Federal de Santa Maria tendo como responsável a professora Jacira Paixão. Em 1976, ocorreu o Primeiro Curso de Especialização em Ginástica Rítmica Moderna, realizado na ESEF do IPA, ministrado por Vera Angheben, com participação de 35 professores/as. Como prova final do curso foi requerida que as/os participantes fizessem uma apresentação de GR com equipes compostas por colegiais por elas/eles preparadas. Tal trabalho culminou na exibição das coreografias no I Festival Gaúcho de Ginástica Rítmica Moderna, considerado como o primeiro evento de GR aberto ao grande público.

Outra protagonista de destaque nos passos iniciais da GR no início da década de 1970 foi a professora Vânia Viana, que começou o desenvolvimento da Ginástica Rítmica na cidade de Santa Vitória do 
Palmar, situada no sul do estado. Lá, formou um grupo da modalidade no Colégio Estadual Santa Vitória, local em que trabalhava como professora de Educação Física. Para constituir o grupo, Vânia selecionou meninas que gostavam de dançar e de fazer ginástica, com a idade aproximada de 11 anos. Com o desenvolvimento do trabalho em Ginástica Rítmica em Santa Vitória, o interesse pela modalidade cresceu e foi assim que Vânia iniciou aulas de escolhinhas no "Ginásio Cardeal" e contava com mais de 100 meninas participando das suas atividades.

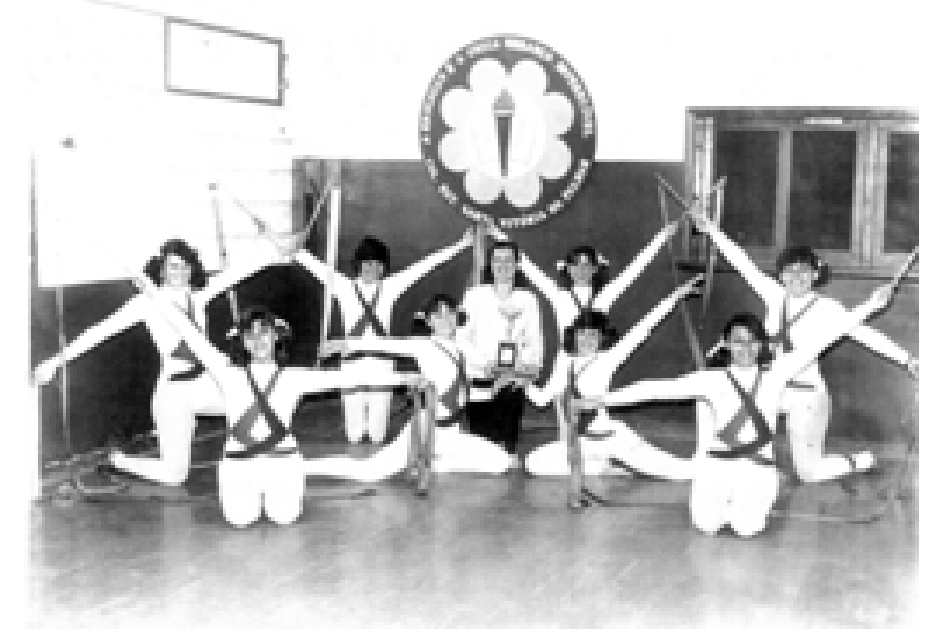

Foto 02: Grupo de Ginástica Rítmica do Colégio Estadual Santa Vitória do PalmarRS ano de 1978. Fonte: VIANNA, V. Grupo de Ginástica Rítmica do Colégio Estadual Santa Vitória do Palmar/RS. 1978. Fotografia.

Enfim, essas mulheres protagonizaram a cena da Ginástica Rítmica no Rio Grande do Sul, sobretudo, com a formação de equipes e promoção de cursos e eventos de divulgação da modalidade. Descreveremos, agora, as primeiras competições destacando suas as regras, os aparelhos utilizados e as músicas escolhidas para a realização das séries.

\section{Competições, regras, aparelhos e músicas: primeiras exibições}

Como já vimos, a Ginástica Rítmica, no início da década de 1970, estava passando por um processo de divulgação dentro do Rio Grande do Sul através da realização dos cursos, demonstrações e da criação de grupos de ginastas. Decorrente desse processo começaram a figurar no cenário esportivo do estado as competições específicas da modalidade. 
A primeira delas se realizou no ano de 1974 tendo como local o Ginásio do IPA, na cidade de Porto Alegre. Neste evento participaram 33 equipes originárias de escolas de todo o Estado e, de certo modo, resultava do trabalho desenvolvido por Vera Angheben junto ao curso de pós-graduação em GR, onde a prova final consistia em cada professor participante criar uma série de GR para um grupo de meninas. Essa primeira competição, contou com o apoio da direção do IPA e do $\mathrm{DED}^{6}$, que legitimou o evento conferindo certificados aos participantes, pois na época a modalidade não fazia parte da Federação Riograndense de Ginástica (FRG) que só reconhecia como oficial a modalidade de Ginástica Olímpica ${ }^{7}$ (ANGHEBEN E BIASI, 2010).

Em âmbito nacional, a primeira vez que o Rio Grande do Sul participou de uma competição de GR foi durante a realização dos VI Jogos Escolares Brasileiros (JEBs) que aconteceram na cidade de Campinas/SP no ano de 1975. Todas as participantes eram alunas do Colégio Americano de Porto Alegre tendo como técnica a professora Vera Angheben. Nesta competição houve uma apresentação individual e uma de conjunto: Cora Maria Casanova, realizou a primeira série individual utilizando o aparelho corda e a coreografia de conjunto com o aparelho bola, foi realizada pelas ginastas: Cora Maria Casanova, Nise Helena Tomasi, Yara Regina Pinto, Rosângela Silva Biasi, Esther Copsten, Elisabeth Schmitt, Lisete Ferlin, Denise Jorge e Maria Inês. Essa participação bem sucedida gerou um grande impulso da GR no Estado conferindo, inclusive visibilidade nacional ao trabalho realizado no sul. Não é sem razão que neste mesmo ano a Confederação Brasileira de Ginástica (CBG), enviou um documento à Federação Riograndense de Ginástica (FRG) incentivando-a oficializar a GR como modalidade na FRG o que efetivamente acabou acontecendo em 1976. Diante dessa institucionalização, a partir de 1976, a modalidade passou a ter um calendário estadual de competições, incluindo: o Festival de Ginástica Rítmica, o Campeonato Interclubes de GRD, o Campeonato Gaúcho de Ginástica Rítmica Desportiva (DED-SEC) entre outros. Apesar dessas competições serem realizadas na cidade de Porto Alegre, contavam com a presença das equipes do interior:

6-Departamento de Educação Física e Desporto.

7-Atualmente conhecida por Ginástica Artística (GA).

Pensar a Prática, Goiânia, v. 16, n. 1, p. 1-319, jan./mar. 2013 
[...] as cidades do Rio Grande do Sul: Estrela, Osório, fazíamos muito essas competições lá. Rio Grande. Um tempo depois desse avanço da Ginástica, nós começamos a trabalhar mais especificamente séries de conjunto. Tínhamos as individuais, mas o conjunto era forte.(VIANA, 2010, p.06)

No início das competições oficiais e amistosas, não havia uma padronização nas regras para julgar as séries apresentadas pelas ginastas. Tornou-se necessário, então, a criação de um manual que continha regras específicas de composição das séries obrigatórias e explicitava quais seriam os quesitos avaliados ${ }^{8}$. Segundo uma das entrevistadas:

Na primeira competição que houve no Rio Grande do Sul não havia, realmente, um código, mas nós recebemos como era uma competição escolar de séries obrigatórias. Já vinha mais ou menos o que era para ser feito. Era mais a técnica corporal e a própria série coreográfica. Não podia fazer além daquilo. Essa era uma das notas e a execução era uma das notas. (EICHENBERG, 2010, p.8)

A aquisição e a confecção dos aparelhos oficiais era uma das dificuldades encontradas na época e uma das alternativas encontradas pelas professoras foi substituí-los por aparelhos adaptados. No seu depoimento, Zelira narra que, na área escolar, o importante era proporcionar à vivência as crianças, ter a capacidade de realizar o elemento mesmo com os aparelhos não oficiais:

$\mathrm{Na}$ época, como ninguém tinha aparelho no RS, a possibilidade era: a corda, que podíamos comprar e fazer, mãos livres, que todo mundo podia fazer, e começamos com a fita, porque se fazia uma haste de madeira, se colocava um aparelhinho que a pesca usava para a fita girar sem enrolar. Era mais fácil. Era uma brincadeira. Não eram as fitas oficiais. Então, já era um pré-desenvolvimento e, os arcos, se trabalhavam com os bambolês de plásticos. Nós forrávamos. Nós tínhamos, no Anchieta,

8-Esse manual e os referidos regulamentos são parte integrante do Acervo do CEME/ESEF/UFRGS, estando também, disponível no Repositório Digital (www.repositorioceme.ufrgs.br) 
os arcos de madeira, mas eram muito pesados para crianças. (EICHENBERG 2010, p.6)

No interior do estado, Vânia relatou que para conseguir os aparelhos necessários ao desenvolvimento de seu trabalho, fazia contato com a professora Vera Angheben, que conseguia trazer do exterior os materiais da modalidade. Os materiais oficiais ainda não eram produzidos no país o que tornava seu acesso difícil e com um alto custo.

Outro ponto importante de ser destacado nessa descrição da prática da modalidade, na referida época, recai no acompanhamento musical durante a execução das séries - uma das características da modalidade, sendo um dos requisitos de avaliação analisado pelos árbitros. $\mathrm{Na}$ década de 70 o recurso para o acompanhamento musical era o piano, único instrumento permitido para a realização das séries. A música deveria ser uma melodia, não sendo permitido o uso de outros instrumentos e nem músicas cantadas:

Eu tinha a minha madrinha que tocava piano muito bem, tinha um primo que tocava piano muito bem. [...] $\mathrm{Na}$ escola tinha piano e nós pedíamos para levar o piano para o auditório. Então, sentava ali e dizia: "não quero isso, quero aquilo, aquela música". Então, ela começou a procurar partituras. Ela fazia os arranjos entre uma e outra e ia costurando, como se diz. [...] Eu construía a série primeiro. A coisa era meio que junto. Eu levava as meninas para lá e dizia o que queria, porque havia os exercícios específicos da bola que não podia fugir. Então, eu ia fazendo e ela ia tocando: "Nesse pedaço eu quero isso". Com meu primo eu fazia melhor. Eu montava toda a série primeiro. [...] Então, ele olhava e já sabia o que ia fazer [...] (VIANA, 2010, p.8 e 9)

A música deveria representar em tempo, força, ritmo, forma, o caráter da série. A série poderia iniciar depois do início da música (era permitido 4 compassos), porém a finalização da série deveria ser idêntico entre a música e movimento. Essas normas eram válidas para séries individuais e de conjunto, buscando transmitir aos que assistiam leveza, harmonia, coordenação e sincronismo.

Enfim, seguindo os passos de Ilona Peuker e já adaptando-se aos regulamentos da modalidade, o trabalho das professoras gaúchas se 
aproximava das instituições oficiais do esporte sendo essa vertente representada como aquela que daria maior visibilidade ao trabalho realizado. Ainda que as apresentações e escolinhas tivessem grande importância, ao assumirem os códigos do esporte, as professoras buscavam dar legitimidade à Ginástica Rítmica projetando nas competições um modo de se fazer ver.

\section{Apontamentos Finais}

As primeiras professoras a trazer a modalidade para o RS tiveram um papel fundamental no processo de divulgação da GR, tanto dentro das escolas como dentro das faculdades de Educação Física. Essas iniciativas alavancaram o processo de reconhecimento da Ginástica Rítmica como modalidade a ser desenvolvida em todos os níveis.

As dificuldades de organização no nível federativo não foram o suficiente para que a GR não se desenvolvesse, ao contrário, a prática ganhou seu espaço entre estudantes e professores e dessa forma conquistou sua identidade demandando sua inserção junto à Federação Riograndense de Ginástica. Ao conquistar esse espaço a modalidade passou a ter maior apoio e suporte para a organização de competições e eventos, que já era uma necessidade para sua consolidação como esporte competitivo e, também, um modo de qualificação de seus praticantes.

Por fim, destacamos, que o material produzido para essa pesquisa, por fazer parte do acervo do Centro de Memória do Esporte (CEME), está disponível para consulta in loco e, também on line, através do Repositório Digital (http://www.repositorioceme.ufrgs.br). Dessa forma, acreditamos poder contribuir para futuros pesquisadores ou pessoas interessadas pela modalidade dentro do estado, podendo assim dar continuidade a pesquisa aqui iniciada, ou também, desenvolver outras pesquisas com enfoques até aqui não explorados. Dar voz e visibilidade aos protagonistas esportivos de determinados tempos e espaços são ações acadêmicas importantes que devem ser cada vez mais incentivadas e desenvolvidas dentro da Educação Física.

Sabemos dos limites desse texto que se mostra muito mais descritivo que analítico. No entanto, por assim ser não deixa de ter relevância uma vez que, a partir dos dados trazidos à memória, é que poderão florescer novas pesquisa produzindo, assim, outras histórias sobre a Ginástica Rítmica no Rio Grande do Sul. 
Historical fragments of rhythmic gymnastics in Rio Grande do Sul: its first professors and their memories

\begin{abstract}
Rhythmic Gymnastics has been developing in Brazil since 1953 and in Rio Grande do Sul since the beginning of the 1970s. Due to the scarcity of its written history, this paper seeks to describe this sport's essence based on the memory of four professors identified as pioneers in their field in this state. Founded on the theoretical methodology of the Oral History and through interviews and other research, we have highlighted not only these professor's knowledge, but also strategies to both adopt and legitimize this sport to be taught in elementary schools as part of their physical education program and also in the training of physical education teachers.

Keywords: Physical Education and Training. Gymnastics. History.
\end{abstract}

Fragmentos de la historia de la gimnasia rítmica en Rio Grande do Sul: las primeras profesoras y sus memorias

\title{
Resumen
}

La Gimnasia Rítmica viene siendo desarrollada en Brasil desde 1953 y en Rio Grande do Sul desde el inicio de la década de 1970. Considerando los pocos registros sobre la historia de la modalidad, esta investigación tiene como objetivo describir sus primordios a partir de la memoria de cuatro profesoras identificadas como pioneras en el trabajo con esta modalidad en este Estado. Fundamentada en el aporte teórico-metodológico de la Historia Oral, fueron realizadas entrevistas y, de sus diálogos con otras fuentes de investigación, identificamos no apenas la actuación de las profesoras pero, sobre todo, las estrategias adoptadas para la divulgación y legitimación de esta práctica en las escuelas de enseñanza fundamental y cursos de formación de profesionales de Educación Física.

Palabras clave: Educación y Entrenamiento Físico. Gimnasia. Historia.

\section{Referências}

ALONSO, H.; INGEBORGE, K. Ginástica Rítmica. In: DACOSTA, L. (Org.). Atlas do Esporte no Brasil. Rio de Janeiro: CONFEF, 2006.

\section{ANGHEBEN, V. Demonstração de Ginástica Moderna no aniver- sário ESEF/IPA. 1972. Fotografia.}

ANGHEBEN, V.; BIASI, M. Vera Angheben e Margaret Biasi: depoimento [ago. 2010]. Porto Alegre: CENTRO DE MEMÓRIA DO ESPORTE - ESEF/UFRGS, 2010.

BARDIN, L. Análise de Conteúdo. Lisboa: edições 70, 2000. 
EICHENBERG, Z. M. Zelira Eichenberg: depoimento [nov. 2010]. Porto Alegre: CENTRO DE MEMORIA DO ESPORTE ESEF/UFRGS, 2010.

FEDERAÇÃO INTERNACIONAL DE GINÁSTICA. Código de Pontuação de Ginástica Rítmica, 2011. Disponível em: http://www.fig.br. Acesso em 27 de agosto de 2011.

FONTANA, P.; NAGAMINE, M.. Ginástica Rítmica. In: MAZO, J.; REPPOLD FILHO, A. (Orgs.). Atlas do Esporte no Rio Grande do Sul: atlas do esporte, educação física e atividades de saúde e lazer no Rio Grande do Sul. Porto Alegre: CREF, 2005. p. 30-32

GARCIA, A.; MARCONATO, B. Atividades rítmicas escolares. Canoas: Ulbra, 2005.

GOELLNER, S. V. et al. Garimpando memórias: esporte, educação física, lazer e dança no Rio Grande do Sul. In: . (Org). Garimpando memórias: esporte, educação física, lazer e dança. Porto Alegre: UFRGS, 2007.

MAZO, J.; REPPOLD FILHO, A. (Orgs.). Atlas do Esporte no Rio Grande do Sul: atlas do esporte, educação física e atividades de saúde e lazer no Rio Grande do Sul. Porto Alegre: CREF, 2005.

MOLINARI, A. M. da P. Ginástica Rítmica: Esporte, História e Desenvolvimento. Cooperativa do Fitness. 2004. Disponível em site: www.cdof.com.br/esportes4.htm. Acesso em 27 maio 2010.

PALLARÉS, Z. Ginástica Rítmica. Porto Alegre: Redacta Prodil, 1983.

PEUKER, I. Ginástica Moderna sem Aparelhos. Rio de Janeiro: Forum, 1974.

ROUSSO, H. A memória não é mais o que era. In: FERREIRA, M. de M.; AMADO, J. (orgs.). Usos \& Abusos da História Oral. Rio de Janeiro: Fundação Getúlio Vargas, 1996.

THOMPSON, P. A Voz do Passado: história oral. Rio de Janeiro: Paz e Terra, 1992. 
UNIVERSIDADE FEDERAL DO RIO GRANDE DO SUL. Repositório Digital do Centro de Memória do Esporte. Disponível em http://www.repositorioceme.ufrgs.br.

VIANA, V. Vânia Viana: depoimento [abr. 2010]. Porto Alegre: CENTRO DE MEMÓRIA DO ESPORTE - ESEF/UFRGS, 2010.

Recebido em: 03/11/2011

Revisado em: 07/12/2011

Aprovado em: 27/01/2012

Endereço para correspondência

vilodre@gmail.com

Silvana Vilodre Goellner

Universidade Federal do Rio Grande do Sul

Escola Superior de Educação Física, Departamento de Desportos

Rua Felizardo, 750

Jardim Botânico

90690-200 - Porto Alegre, RS - Brasil 